\title{
6 The ethics of research on old age
}

\author{
Maria Łuszczyńska
}

Dealing with the ageing of societies not only makes it necessary to adapt medical, social and economic services to the needs of seniors but, above all, to broaden the research into and diagnosis of the needs of the oldest group of citizens. Research into ageing impacts all disciplines, from medicine and the biological sciences to economics, law and the social sciences - anywhere where seniors become the subjects of research.

This chapter considers ethical standards, as modified in response to the dynamic development of research into old age. The purpose of the text is to define ethical requirements regarding the acquisition of older people as respondents of research, particularly in relation to the researcher.

The chapter discusses the boundaries of such a researcher's knowledge and insights, data confidentiality and ways to provide respondents with anonymity and a sense of security, as well as issues arising when conducting research on sensitive issues in which a group of elderly people talk about their emotions, feelings, experiences, needs, motivations and privacy.

In light of developments in social research, various attempts are made to systematize the relationship between ethics and methodology.

\section{Introduction}

The extension of human life and improvement of its quality are becoming an indisputable fact, noticeable in practically all societies in which there is access to modern medical, rehabilitative and preventive solutions and in which the social, political and economic situation is conducive to supporting the elderly. Old age as a multidimensional phenomenon that affects ever wider social groups is becoming a reality. It should also be emphasized that old age treated as a multifaceted phenomenon - present in various areas of human activity, from the dimension of individual human life through the social, economic, political, medical, legal, cultural, educational and other dimensions - is extremely diverse.

The question of what kind of meaning will ultimately be assigned to old age depends on the individual trajectories of older people's lives, subjective political perspectives and individual ways of interpreting old age in the contexts of various disciplines of human knowledge. Old age is diverse - just like the people who, by belonging to a specific age group, become interpretative determinants for the phenomenon itself.

In this sense, both old age and older people may become the object of researchers' interest. In recent decades, there has been a huge increase in interest in research on old age and the elderly in very diverse research contexts (Uhlenberg, 2009). In virtually all countries of Northern and Western Europe, North America and Asia, scientific institutes operate 
and conduct active research, carrying out various types of scientific studies, including these pursued at the request of governments. An overview of global online resources has shown that around 300 scientific and governmental institutions - along with organizations that focus on the development and research of old-age phenomena as their main purpose operate worldwide (http://info-centre.jenage.de/ageing/centres-and-institutes.html). The quantity and scope of interest in old age expressed in research are very high, and their main driver is the search for systematic solutions in dealing with the phenomenon of the global ageing of humanity.

Why is there such a large increase in interest in the subject of gerontology? It can be affirmed that due to the universality of this subject and the fact that sooner or later old age will apply to everyone, researchers are looking for answers to one general question in their studies: how can one experience old age well? This question is directly related to another issue, namely, how can one properly prepare oneself for old age? The very scope of these questions, and thus also of the answers obtained, is firmly embedded in ethical space, because when we ask about a "good" old age we mean a state in which our psychophysical condition, social relations, economic situation, legal status and educational activity guarantee us a dignified experience of old age - one that respects our rights, needs, autonomy, self-determination and individuality. Hence, every study - from one that searches for medication to insure longevity and conducts medical experiments, to psychological research defining a mental state or various disorders, to social research showing changes in roles, stereotypes or activities - is by nature ethical research. It is extremely important for gerontological researchers to realize how thoroughly their research should be thought out, in terms of respecting certain general ethical principles at every stage of the research.

An ethical perspective is present, regardless of the methodological perspective of the research discipline. Despite the fact that old age is subject to assessment by many disciplines and fields of science that apply various methodological approaches, the ethical premises of this research are common to all of them. Ethics in this sense has a meta-interdisciplinary dimension. Analyzing the detailed aspects of gerontology that can be engaged with ethical reflection on research into old age will be the main goal of this chapter.

Many references in this text will connect with the social dimension of research, but only because that field is largely developing reflection on the ethics of gerontological research, thanks to the tools that it has at its disposal. I am not asserting that medical or biological sciences do not refer to ethical thought when studying the ageing processes (Cash et al., 2009). On the contrary, they were the first fields - presumably in response to unethical experiments during and after World War II - to show concern for establishing ethical principles and norms in medical research; committees, bodies and ethical codes were thus established in connection with medical experiments on human beings. However, the ethical standards of medical research are insufficient for social research, and the development of ethical reflection (and a justification for such ethical reflection) belongs to the humanities and social sciences (Ramcharan and Cutcliffe 2001). Hence, references to codes of ethics with a social character appear in this chapter.

The purpose of this chapter is to deepen the awareness of the researcher - regardless of the field of research in which he or she works - of how deeply ethical reflection is rooted in methodological choices and of how much time should be spent on asking and resolving questions of an ethical nature before the researcher even begins research procedures. The chapter also attempts to analyze the researcher's relationship with the respondent from the perspective of ethicality, as well as to propose "decisive questions" on various ethical issues at specific stages of the research process relating to the elderly. 


\section{Ethics in academic research}

The essence of scientific research is the systematic contribution to building verifiable scientific knowledge. Equally important in this process are the sources of knowledge, the way in which it is acquired and interpreted, and ethical reflection on the purposefulness of research and the research procedure itself. Ethical issues arise from the particulars of the problems analyzed in gerontological research and of the methods used to obtain accurate and reliable data.

Sources of ethical problems can be (1) the research problem itself (e.g., social stereotypes of the elderly, life expectancy, physical condition, mental disorders, intelligence determinants, new technologies supporting fitness, the level of fear of death, everyday life in care institutions or sexual activity); (2) the environment in which the research takes place (a hospital, social welfare home, university of the third age, family home, church organization or location); (3) research procedures and methods required by the study design that may adversely affect the study's participants or the results themselves (e.g., using an experimental method, employing concealed observation techniques or utilizing group interviews where the researcher must control the group process); (4) respondents themselves (e.g., people who are physically or mentally disabled or who are intimidated in a position of implied submission, such as residents of a social welfare home); (5) the type of data collected (e.g., personal, sensitive or confidential data); and (6) the relationship between the researcher and the research subject.

The ethics of scientific research should be understood as

a certain specific, relatively distinct branch of normative ethics, which examines the ethical aspects of research activities performed in the context of science. The main task of this discipline is to establish and justify the rules which, from an ethical point of view, actors should observe. Within such rules - the principles of good research practice - I distinguish three groups: (1) rules regarding research reliability, (2) rules regarding fidelity to research participants, and (3) rules regarding the usefulness of the research results.

(Galewicz, 2009)

Ethics is a science of morality, which in turn encompasses the practice of adhering to recommendations and realizing moral values. Thus, the debate on morality as a practice has an ethical dimension (Górniewicz, 2016). Research ethics can be a set of values and attitudes that scientists respect and adopt in order to incorporate moral norms and values into the research process. This applies not only to the research procedures themselves, but also to the way of dealing with the current thematic literature and of disseminating research in the form of scientific texts. It should be clearly realized that the commitment to comply with ethical rules is immanent in all scientific activities. Thus, one of the elements of establishing a research outfit is for a researcher to become familiar not only with the ethical requirements that apply to the particular research being pursued, but also those applying more broadly to all scientific activities.

Various codes and sets of ethical principles that set standards of conduct and indicate the consequences of non-compliance can provide a point of reference when considering the ethical context of research practices. In Poland, since 2012, the most general norms for ethical conduct in academic research are presented in the Code of Ethics for Researchers (KEPN), developed by the Committee for Ethics in Science of the Polish Academy of 
Sciences (https://instytucja.pan.pl/index.php/kodeks-etyki-pracownika-naukowego). It was modeled on the European Code of Conduct for Research Integrity, a code published in 2010 (https://allea.org/code-of-conduct/) and developed by the European Science Foundation (ESF) and the All European Academies (ALLEA), which was intended as a benchmark for use in EU countries for creation of their own ethical codes. Shortly afterwards, the 2012 Sociologist's Code of Ethics was created in Poland (Kodeks Etyki Socjologa, approved by the general meeting of delegates of the Polish Sociological Association in March 2012: http://pts.org.pl/wp-content/uploads/2016/04/kodeks.pdf). Worldwide, guidelines for the norms and principles of ethical social research can be found in the Code of Ethics of the American Association for Public Opinion Research (AAPOR Code of Ethics: www.aapor.org/Standards-Ethics/AAPOR-Code-of-Ethics.aspx), created by the interdisciplinary association of researchers in the field of social sciences (sociologists, psychologists, political scientists); in the International Code on Market, Opinion and Social Research and Data Analytics, developed jointly by the International Chamber of Commerce (ICC) and ESOMAR, formerly the European Society for Opinion and Marketing (www.esomar.org/); in the International Code on Market and Social Research (http://ethics.iit.edu/ecodes/ node/5178) which in Poland is obligatory for members of the Opinion Research Section of the Polish Sociological Association. In addition, research and academic institutions set up internal ethics committees and commissions, which in the context of these institutions deal with questions of the ethicality of individual research projects.

The fundamental premise of all these codes is their rooting in fundamental ethical principles, such as respect for human dignity and life in all its manifestations, truthfulness, honesty, responsibility and a recognition of the right to freedom of belief and to property. These principles are axionormative, i.e., their content is beyond dispute. Around these values, KEPN lists the following principles that directly result from specified values:

1 conscientiousness in presenting the goals and intentions of planned and conducted research;

2 credibility in conducting research, critique of one's own results;

3 objectivity, i.e., basing interpretations and conclusions solely on facts and verifiable data;

4 impartiality in the approach to the examined or presented problem;

5 independence from external influences on the execution of research;

6 openness in discussing one's own research with other scientists;

7 transparency in the collection, analysis and interpretation of data;

8 responsibility toward research participants and research subjects;

9 integrity in recognizing the scientific achievements of those who indeed deserve it;

10 caring for future generations of researchers and educating them in accepted ethical norms and standards;

11 courage in opposing views that are contrary to scientific knowledge and practices that are incompatible with the principles of scientific integrity (Code of Ethics for Research Workers, 2017).

Reflection on the need to introduce and enforce ethical standards in gerontological research derives primarily from the conviction that it is still a field of knowledge whose status is being shaped as we speak, which in the course of research and study is still developing methods and standards and also specifying problems and areas for research. The call to care for the ethicality of gerontological research is also linked with the broad theoretical 
postulate - which in Poland was first outlined in this form by Florian Znaniecki in 1919 that all research and the conclusions resulting from it be based on the so-called "humanistic coefficient" (Znaniecki, 1919). It is a component of a wider trend, known as humanistic sociology.

The humanistic coefficient is understood as a particular methodological directive in the study of a given culture, which prompts the researcher to take into account the experience of people and their activities - the meanings or importance that the people being studied attribute to the examined objects in specific communities. According to Znaniecki, the sociologist should relate phenomena to empirical entities. The observation of social systems equipped with the humanistic coefficient is different from observing natural systems. Observing values should take into account the experience of the subjects in this process. In this context, there is no arbitrariness in applying a method; the world of values must be studied using the humanistic coefficient. The principle of the humanistic coefficient led Znaniecki to a new theoretical perspective that was innovative in comparison to existing research approaches, by incorporating the cultural aspect into social research. As applied to the human being, the humanistic coefficient opened up new possibilities for studying the cultural reflexivity of an individual and his or her cultural becoming (Hałas, 2010, pp. 145-146).

The postulate of being guided by the humanistic coefficient (on the basis of Znaniecki's thought) does not encourage the adoption of a subjective perspective in research; it is a statement about something much more important - namely, that a person is the creator of values, as one who is a value himself or herself. Because a human being has value, he or she has both meaning and axiological importance, which is changeable and historically relative. In cultural becoming, the natural world of things can become transformed into values, but also vice versa - i.e., values can become things, when they present themselves as permanent and immutable meanings, given once and for all time. Such a process of reification of values can be observed in a world in which the declarative layer of the description of the world does not go hand in hand with action, as grounded in such declarations. The same can happen to values, which will "reflect" the researched reality in a certain guise when employed in research, including gerontological research.

In Florian Znaniecki's theory of the humanistic coefficient, an individual constructs or reconstructs many cultural systems, including social systems, which are the source and material of his or her subjectivity. As one performing social roles, the individual can even be understood as a social system, but he or she is not closed within it. In this conception, culture as a source of subjectivity becomes a source of individual independence from social systems, insofar as the individual - as a center of action - learns, understands and participates in creating cultural systems. In this sense, it is an "open" subjectivity, if we can refer to Roman Ingarden's thought (1987, p. 125).

Translating this into the area of the social sciences, if in light of the humanistic coefficient we take as the object of research the opinions of older people on a selected topic and consider these opinions important and sense-creating, then in order to analyze these opinions, they must be associated with motivations (i.e., tendencies to certain behaviors), attitudes (relatively persistent sentiments toward someone or something), social needs (conscious or unconscious aspirations resulting from situations and assimilated values), accepted and implemented social norms (spontaneously shaped prohibitions and dictates approved in a given environment) and values specific to a given community tangible and intangible objects, to which people attach particular significance (Dyoniziak, 1997, p. 14). 
What does the adoption of such a perspective mean for the ethics of gerontological research? Well, the recognition that the social reality is first and foremost as the respondents (and not the researchers) see it leads to a very careful building up of the research relationship with the respondents. It is advisable to use an objective-subjective approach in sociological research, i.e., a description, diagnosis and interpretation of the social world from the perspectives of both the researcher and the respondents. The researcher, wherever possible, must avoid valorizing the behaviors, feelings, opinions and attitudes of individuals, groups or entire communities. If this is not entirely possible for various reasons (e.g., methodological), the researcher must be open and honest toward the respondents. The emphasis on honest ethical reflection on the research relationship between the researcher and the elderly becomes a determinant of the entire research process in which all ethical considerations are subordinated to the good of the studied person. The researcher's goal, the research results and the interests of other parties involved in the research should stay at the background of the process. Hence, the measure for verifying the sense and ethical correctness of all research decisions is the categorical imperative of Kant - in which human dignity is a fundamental value and the use of the human being as an instrument is rejected, in accordance with the imperative's two premises: "Act only in accordance with that maxim through which you can at the same time will that it become a universal law" (G 4:421; cf. G 4:402) (Kant, 2002, p. 37) and "Act so that you use humanity, as much in your own person as in the person of every other, always at the same time as end and never merely as means" (G 4:429; cf. G 4:436) (Kant, 2002, pp. 46-47). Referring the theoretical perspectives and principles mentioned above to methodological considerations regarding gerontological research, it seems important to analyze some of them in more detail. In research on old age, what generates the most ethical difficulty is the responsibility to the participants of the study, as well as the need for objectivity, diligence and credibility in reflecting upon one's own assumptions and research results. The rest of this text will be dedicated to a deeper analysis of these principles in relation to the ordering of the research process.

\section{Ethically relevant dimensions of research on old age}

If one is looking for aspects of gerontological research in which ethics play a significant role, then it is necessary to differentiate several areas. The first thing to be subjected to ethical reflection should be the intentions of the researcher - and not only the initial ones that lead to the selection of the research problem, but also the later ones that decide the course of study and interpretation of its results. By intentions, I have in mind those factors that initially trigger the thought or emotion that leads the researcher to deal with a given research aspect. Every study starts with a certain intellectual spark or personal experience with or interest in specific issues. The researcher's life experience - undergoing situations that cause irritation, satisfaction, anxiety or trauma - can often contribute to the selection of research topics, as well as the need to study the thematic literature. This choice is always situated within a broader "axiological climate". The intentions to choose a topic should be subjected to ethical reflection, preferably in cooperation with and during joint discussions with specialists who can help the researcher decide whether the choice of the topic to be studied and the intentions behind it will not lead into a trap of distortion and will not cause the engaged researcher to fail to fulfill the requirement of objectivity.

Similarly careful analyses of one's intentions should be conducted at every stage of the research in which the researcher's subjectivity confronts the subjectivity or intersubjectivity of the information conduits, i.e., the research subjects. The discrepancies that then may 
be revealed may distort the course of the study itself, violate the research relationship and later affect the method of development or interpretation of the results.

When analyzing intentions, it is advisable to recognize possible discrepancies between what the researcher and a study's subject - and between what the study's implementer and commissioning party - consider important. These three spaces may not meet each other, remaining divergent throughout the planning and implementation of the study. The question of how to deal with this situation and what to decide with regard to the continuation of research and evaluation of the study's results is a question with an ethical character. Often, a thorough analysis of the interests, goals and values of each party that subjects these elements to an in-depth process of understanding makes the clues to these questions clearer and the answers simpler. Provided, of course, that one remembers the axionormative premises that underlie gerontological research.

The sphere of the research relationship between the researcher (or researchers) and the subjects - the elderly - is a very important axiological space. As respondents, older people belong to a group of persons "vulnerable to harm". It should be emphasized that this group is extremely diverse in terms of demographic and social features, such as education, place of residence, family situation, interests, social relations, health status, economic situation, level of activity, passions, life experience, social engagement and other features that distinguish members of the population of elderly persons from one another. Moreover, age - despite the common tendency to classify all older people as belonging to one age category - is increasingly a feature that differentiates the senior population. The situation will differ for a person who has just left the labor market, for a person who has been a pensioner for several years and maintains a relatively good level of independence, and for an elderly person who requires support and care because he or she is not fully independent (or is completely dependent). Elderly persons' vulnerability to harm is an inherent result of their psychological situation. Regardless of their actual mental condition and health, an objective common feature of this social group is a lesser or greater awareness of the fact that old age is the last stage of life - that after old age there is only death, and that this is an irreversible process. Different people cope with this awareness differently, but, regardless of this, it is a situation that can cause unexpected reactions, unpleasant emotions or even a worsening of one's health condition. Older people have a reduced degree of autonomy, when compared with the level of autonomy they enjoyed at earlier stages of their lives. It is often linked with their economic, social and health situation. Of course, there will also be exceptions, as for some people the situation of ageing will bring a positive experience; however, as a working hypothesis, it is assumed that, in general, at the levels of health, economic condition, or family and social relations (or from all of these perspectives), old age may reduce one's sense of independence from people, from things and from social support systems.

Older people who are subjects of social research are also susceptible to influence and manipulation. They tend not to reveal their situation to the same degree that they experience it; usually, this involves a tendency to present their perceptions, beliefs, desires and expectations as better than they are in reality. This can be illustrated by an example of research conducted in which older people were asked to assess their contacts with family; most of them rated them as great or very good. When asked about the frequency of such direct and personal contact (i.e., not by phone or email), they stated that it takes place once every three months, on average. The correlation showed that an assessment of contact as very good also occurred when such contact happened twice a year, on holidays. This example reveals the tendency of seniors to be wary in revealing their true assessment of their situation. While it can be 
assumed that some seniors are happy having such rare contact with their families, this tendency can be treated suspiciously before it becomes the norm.

Similarly, research with seniors who are permanently in care institutions where their fate depends on other people - family or staff - should be conducted with great caution and care. In such situations, the seniors will often have objections to revealing accurate information about themselves, fearing that it might be used against them. Health status, level of strength, stereotypes, limited or absent autonomy, cognitive impairment (associated with damage to the senses or mind) or the current overall state (mental, physical and emotional) may cause the respondents to collapse under the pressure of authority - which in their eyes may be represented by the researcher.

The research relationship between the researcher and the respondent should be - as is the case with groups of subjects "vulnerable to harm" - characterized by a high degree of acceptance of the respondent and by patience and openness, so as to eliminate existing stereotypes or superstitions (including in the researcher) about the senior population. The climate of the research relationship is supported by minimum requirements that the researcher must fulfill toward the respondent. When we analyze the ethical-methodological context of sociological research, we pay attention primarily to the research process, especially when the relationship between the researcher (or pollster) and the person who is the subject of the research is a face-to-face relationship. Above all, it is possible to point out six basic ethical principles, which, as closer analysis reveals, very often are not (or cannot be) fully applied, due to the particulars of the adopted method or research technique. These principles include:

1 the principle of voluntariness,

2 the principle of informed consent,

3 the principle of doing no harm (of not jeopardizing the subject),

4 the principle of anonymity,

5 the principle of confidentiality,

6 the principle of privacy,

7 the principle of truthfulness regarding the identity of the researcher, the purpose of the research, the institution conducting the research and the commissioner of the researcher.

The principle of voluntariness (expressing agreement to participate in the study) by the respondent should be based on a precise definition of what is the purpose of the study, what issues (including sensitive ones) will be raised in the study, what the course of the study will be and how the results will be used. Expressing consent based on the information possessed is absolutely essential in situations where the subjects are at risk. Research subjects must know that their participation in a study is completely voluntary, and they should receive full information about the benefits, rights, risks and dangers of their participation in the research beforehand. In principle, obtaining consent to participate in research not only respects the individual's right to self-determination; it transfers onto the respondent the responsibility for potential negative effects that the research might have for those participating in it. Expressing consent also reduces the legal responsibility of researchers, as it confirms the voluntary nature of the participation of subjects in the conducted research.

The concept of the right to express informed consent based on given information likewise arose from the acceptance of social norms, cultural values and legal regulations. Although the principle of obtaining the consent of potential subjects based on the information that they possess has gained wide acceptance, researchers may still have problems 
applying it. This is because in certain cases, researchers may not fully understand what it means for a person to be informed or how they can be sure that the person has understood the information provided to them. A problem may also arise due to the selection of information to be shared (or not shared) by the researcher, if, for example, the researcher wants to carry out an experiment that involves concealing from the respondent whether he or she is in the control group or experimental group.

The respondent's decision-making procedure comprises four aspects: competence, voluntariness, full information and understanding (Frankfort-Nachmias and Nachmias, 2001, pp. 94-95). The components of the consent procedure should include:

- fully explaining the procedure to be followed and of the purpose that it is supposed to achieve;

- describing the inconvenience that may arise and the extent of reasonably expected risk;

- describing reasonably expected benefits;

- disclosing appropriate alternative procedures that may be beneficial to the subject;

- $\quad$ providing responses to all questions regarding the research procedure;

- making it clear that the person making such a decision has a free choice and may at any time refuse to continue participating in the study without any negative consequences to himself or herself (Ethical Guidelines for Good Research Practice, 2011).

Another principle that applies in research relationships, especially in medical and psychological research, is the principle of doing no harm (of not jeopardizing the subject). It can be said that it is closely related to the two previous principles, and it applies to situations in which the participation of the respondent in the study has a highly experimental nature (for example, in the testing of a new drug or in a psychological experiment relating to sensitive issues, like the motivation for actions or experiences related to unpleasant emotions). After several widely known psychological and medical experiments (e.g., the experiments of Stanley Milgram from the 1960s, of Philip Zimbardo from 1971 or of Laud Humpreys from 1975), the principle of non-harm in such experiments became a foundation of protections in the face of study participants' lack of awareness knowledge.

The obligation to insure the anonymity of respondents and the obligation to insure the confidentiality of collected data are not mutually exclusive. They should be met at all costs, unless the researcher has come to a previous agreement with the subjects on these matters. Researchers insure anonymity by separating data about the identity of the subjects from the information that the individuals provide. A studied person is considered anonymous if the researcher or other people are unable to associate specific information with specific research subjects. Therefore, if information is provided anonymously - thereby entailing that the researcher will not be able to associate names with the obtained data - then the identity of the studied person remains secret, even when he or she has provided very personal information.

One of the easiest techniques to guarantee anonymity is not to ask for names or other information that could identify a person.

Persons participating in social science research are often assured that the information they provide will be kept confidential - i.e., information that identifies the respondents will not be made public. This is accomplished through the removal of identifying data, the introduction of broad categories for data (e.g., using the province instead of the city, the year of birth instead of the exact date of birth, or a profession instead of the name of a specific workplace). 
An important principle in social research, especially in the context of the elderly, is the principle of privacy. It's possible to speak of this in three senses: (1) regarding the scope of collected data, when the data relates to issues from the private life of the respondent and, because they are private, expose the respondent to potential peril; (2) regarding the space for conducting the research, with the respondent deciding in what space (from fully private to fully public) his or her sense of privacy can be most fully guaranteed; and (3) regarding the scope of identifying personal data with information provided in the study; this aspect concerns the possibility of identifying personal data and linking it with the answers given by respondents. For example, information about income will remain private, if only the researcher has access to it. However, if such information (including the amount of earnings and names) is disclosed to third parties, then there is a violation of privacy.

The last of these principles concerns disclosing the truth about the identity of the researcher, the purpose of the study, the institution conducting the research and the commissioner of the research. This rule is often not respected in the case of marketing research or in studies based on undisclosed observation of participants. (Regarding ethical problems of participant observation, cf. Chomczyński, 2006.) If disclosing the identity of the researcher, the purpose of the study or the commissioner can distort the result of the study - and, in particular, have an impact on its effects - then researchers may decide not to provide the respondents with this data.

The abovementioned principles are canonical in building a research relationship with the respondent. This does not mean, however, that all researchers employ such a procedure in its entirety, as they often exclude some of its elements because they disrupt the results of their research. This is always a discretionary exclusion, and it places the researcher in the situation of an ethical dilemma.

In academic research - especially that in which the subject of the study is a person, potentially an elderly person - two rationales are usually in conflict: the good of the academic research and the good of the studied person (respondent). The basic ethical problem in social science research is that in many cases the interference in the psyche of the respondent (the examined person) can be as deep as in psychological research - with the difference being that both the researcher (sociologist) and the examined person are sometimes unaware of this.

While the principle of doing no harm to subjects is quite clearly defined by institutionalized rules whenever a study involves interference with the human body (in the biological sense) - such as in medical experiments (e.g., the person who is to undergo such an experiment should complete an informed consent form) or in psychological experiments (regarding interference in the human psyche), the scope of non-harm remains unspecified with regard to social science research. This is so because the consequences of questions and requests addressed to seniors as part of research are unknown, even if the research's goal itself is seemingly innocent (Walczak-Duraj, 2013). In such a situation, the consequences of participating in a study are unpredictable, and thus it is impossible to completely protect an elderly person from the effects of his or her participation in the research.

Therefore, in the context of the research relationship, it is worth asking yourself the following axiological questions to verify your approach:

- Is it justified to involve selected elderly people in the study?

- Is each respondent treated as subject? Do I see him/her as a human being or only as a data source? 
- Is the respondent's perspective respected? Are differences that might arise respected, registered, heard?

- Has the research guaranteed all minimum rules of the research relationship: anonymity, confidentiality, privacy, voluntariness, openness?

- Does the given study have a chance to achieve its goal - which is to get to know the studied reality more broadly and then to improve the quality of life of people representing the studied population?

- Is the researcher the right person to carry out research on the given topic in the given group?

- Will research ultimately contribute to more than just developing the researcher's academic career?

\section{On ethical elements in the research process}

Another area around which it is possible to arrange axiological issues is the dimension corresponding to the course of the study. When undertaking research on old age, we are not always aware that ethical problems occur at every stage of the research process: first, at the stage of conceptualization, when we select a topic and define research groups; then at the stage of selecting methodology and research techniques and constructing research instruments - and then, after that, at the testing stage; at the stage of analyzing and interpreting data (with the problem of imposing the researcher's value system on the respondent's value system); and, finally, at the stage of publishing the developed and interpreted empirical material (Brzeziński, 2015). At each of these stages, ethical reflection is inevitable, if we want to achieve the general objectives of research - namely, to obtain maximally accurate, certain and general knowledge that is as straightforward as possible and has maximal information content (cf. Dąmbska, 1967; Jevons, 1960; Nagel, 1970; Such, 1972; Pilch, 1998). Thanks to such knowledge, it is possible to formulate laws of science and its regularity. In this sense, the methodological context is closely connected with the axiological context.

Below, we present an attempt to analyze selected ethical aspects in relation to the following stages of a study:

1 conceptualization

2 conducting the research

3 analyzing data

4 presenting the results.

\section{Conceptualization}

Conceptualization is the stage of research when the particular research topics are clarified and answers are given to the question of why the research should be performed at all. The reasonableness and sense of given research was discussed earlier in this chapter, and the questions raised there can be used at this stage. Planning for a study's funding sources is also a significant factor. In strictly academic research carried out at the request of an academic institution, the financial source as such is not a subject of controversy. Debate may arise when the research has a dual scientific and implementative nature, in accordance with current trends to encourage researchers to strengthen collaboration with a country's so-called "second sector" (i.e., the private sector). In such collaboration, the factor of 
expectation of financial profit may put researchers in a situation of ethical dilemmas between the expected profit of a company that commissions research and the good of the respondents. An example of such a dilemma may be a study that ultimately did not take place in Poland, regarding the reverse mortgage system. A certain banking consortium tried to introduce this instrument into its banks' offers, and it needed research not only to determine the scope of interest in this instrument among a group of older people but also to provide data on the seniors' precise health conditions and health habits; the research would also have tested a proposition to put seniors under the care of specific medical clinics at the point of entry into the reverse mortgage system. Such expectations seemed to the researchers to violate the well-being of the respondents and, as a result, the research was not conducted for ethical reasons.

At the stage of conceptualization, a choice is made regarding the study's type of participants, and if they are to be elderly people, then all observations made in this chapter about building a research relationship with senior respondents remain pertinent.

Other ethical decisions must be made when selecting research methods, others when designing research instruments and yet others when creating the language to be used in the research. It should be considered whether a chosen method is adequate in view not only of the study's purpose but also of the capacities of the respondents themselves. The same applies to the particular instruments composed for the given method. If the method, tool and language that we use are not adapted to the particulars of the respondents, then stereotyping or exclusionary tendencies will increase as a result of this research, because its results will show the respondents to, in some areas, fall short of certain hypotheses and expected results.

The same applies to the language used in the instruments created. If it is incomprehensible, stigmatizing, manipulative or unclear, then the results of the study will reflect similar characteristics, while the respondent, not the researcher, will be held responsible for the quality of the study.

Questions that are worth asking yourself at this stage of the research process regarding ethical reflection are:

- Is the chosen research method suitable for the abilities and particulars of the examined group?

- Is the language used in the research instrument understandable to respondents?

- Does implementation of the planned research procedure transgress the boundaries of intimacy?

- Does the survey assume voluntary participation of respondents?

- Can the process of the study cause any mental or emotional harm to respondents?

\section{Conducting research/collecting data}

The stage of data collection should be preceded by obtaining subjects' informed consent, as mentioned earlier. Informed consent may vary in scope for different researchers. It should include voluntariness of participation, the possibility of resigning from participation in the study at any stage and the possibility of withdrawing consent to use the data obtained. In order to obligate researchers to continually determine what effects their research work may have, ethical codes include provisions about the need to protect research participants from harmful consequences; importantly, even the consent given by study participants does not release researchers from this obligation. 
An issue that is worth noting with regard to seniors is that they tend to too quickly agree or refuse to take part in a study. The challenge for the researcher is to convince a senior to listen to all of the information needed to make a decision about participation in the study, so that this consent is actually informed. Elderly people are prone to make decisions under the influence of emotions (anxiety or an eagerness to be supportive); therefore, this aspect of research associated with an awareness of participating in the study must be further elaborated by the researcher. The process of reaching informed consent ought to be carried out responsibly, and, while implementing it, the researcher cannot think only about his or her research interests but should, in a spirit of broader responsibility, care about achieving an autonomous decision by the elderly person.

Worthy of particular emphasis is the situation of examining elderly people whose disability or physical or mental illness prevents them from taking a fully independent decision to participate in the research. Often studies of such people involve participation of an intermediary, from whom the researcher may be unable to obtain information, if a subject is presumed to be uneager to have such information disclosed. This means that the rules for receiving informed consent should also be presented to all family members, employees and caregivers of the aforementioned social categories whose dependent seniors may be the subjects of a study.

Older adults who are in a situation of limited autonomy (e.g., because they are under the care of a family or in a care institution) largely decide to participate in the study based on how they perceive the researcher. If he or she is treated as an "outsider" or authority and in addition - is conducting comprehensive research (e.g., of a subject's family or employees of the institution in which the senior is located), then information provided by a subject during the study might be distorted due to the fact that the researcher may be seen as "disloyal". Hence, the researcher's great challenge in this situation is the requirement of "double neutrality" (Borkowski, 2013, pp. 14-18) - an attitude in which the researcher in no way (not even the least suggestive) endorses any of the antagonistic parties.

Another issue that raises ethical controversies is the reliability of collected data in a situation where the respondent (the elderly person) manifests some kind of communication disorder. Such disorders do not have to be associated solely with cognitive impairment or poor senses. They can simply be associated with misunderstanding, uncertainty or taking on the role of a participant in the study. In this situation, the researcher has the task of ensuring the understanding of the respondent - repeating and clarifying questions in a patient manner - while remaining neutral and not taking shortcuts.

Difficulty in understanding the research scope expressed by research questions and tasks may give rise to a variety of feelings in the researcher - discouragement, impatience, boredom, fatigue, resignation, anger, nervousness and other sentiments. Contact with the elderly may lead the researcher into a confrontation with his or her own issues. On the one hand, contact with an elderly person generates openness on the part of the interlocutors as a reaction to the openness of the senior; on the other hand, however, it often inspires digressions, the telling of one's life story, and avoiding statements about the main topic. A certain tone of expression may cause various reactions in the researcher, especially if in the context of his or her research there is an awareness that this state of life may become the researcher's own, sooner or later. Confrontation with old age during the study may be personal, thus obscuring the research results and causing various feedback reactions, such as rebellion, anger and impatience.

It is a great challenge for the researcher to anticipate that such situations may take place and to prepare for them ahead of time. As part of this preparation, vast areas of education for old age are opening. Thus, another ethical issue to be decided by old-age researchers is 
to what extent the researchers themselves should be familiar with their own ageing process. To what extent can such "homework" regarding the passage of the time of one's own life protect the researcher from disruptions in the process of collecting data and from distortions in their interpretation?

Ethical questions worth asking at this stage of the research process include:

1 To what extent did the researcher insure the autonomy of the respondent when making decisions about participation in the study?

2 Does the course of the study protect the respondent's dignity? Does the researcher transgress the limits of influence, manipulation or the exertion of pressure?

3 Is there a climate of trust during the study? What else can be done to make the respondent trust more?

4 Has the researcher used manipulation, distortion or selective means of presenting information about the study to attract the participant?

5 How does the researcher deal with possible problems with understanding the respondent? Do these disorders have an impact on interpretive simplification, the way in which the study is conducted or the resignation of the researcher/respondent?

6 To what extent do the researcher's emotions toward the respondent influence the course of the study?

7 To what extent is old age as a research topic internal/external to the researcher?

\section{Data analysis}

The data analysis phase is preceded by transcription of collected research material (interviews, observations, video recordings, etc.) or encoding of quantitative data. In this phase of research, care should be taken regarding the quality of the records and decisions should be made about how the statements of the respondents will be recorded, especially if they do not express themselves consistently, precisely and eloquently. With regard to the expectation of research reliability, quotes from respondents' statements should be reproduced in the transcription literally, and then quoted in the same way in the next research stage, i.e., in the presentation of the collected material. However, a researcher's care for the way in which respondents are perceived more generally (beyond simply literal quotations) is an area in which the researcher has an influence on the social perception and image of the elderly - and this yields a dilemma that is indeed ethical in nature.

On the one hand, the reliability of the research material should be attentively and carefully considered. On the other hand, though, the researcher should be aware of the consequences of literal quotations of the respondents' statements.

Analysis of data entails not only its reliable reproduction in the course of transcription or encoding but also a way of interpreting the collected data. Interpretation may involve placing a respondent's statements and behaviors on a spectrum from being considered extremely abnormal to completely normal, and thus may become a source of (de)stigmatization. Respondents' statements can also be presented as manifesting an acceptable difference.

In this activity - the interpretation of a study's results - the distinct value systems of the researcher and the researched also may pose a problem. This is especially emphasized in a situation where the researcher represents a population of young, working people who are at a different stage of life from seniors. The clash with the differing perspective of older people may cause an overinterpretation or misinterpretation of seniors' statements in the broader context of their psychosocial situation and other semantic contexts. 
This is the stage at which the researcher is the most independent in his or her analyses and is subject to a constant temptation to make distortions that are convenient for him or her. Therefore, during this process it is very important to have a consultative team that can act as a supervising body with regard to the facts that were collected in the stage of data collection.

At this stage of the research process, it's worth the researcher asking him- or herself the following ethical questions:

- Have the source data been recorded reliably and accurately?

- Is the interpretation of the results consistent with/contrary to the objectives of the study?

- What corrections have been made to the source data? What has been distorted? What was omitted? What significance do these modifications have for the whole picture?

- Do all the research conclusions reflect the facts/statements of the respondents?

- Have the conclusions been evaluated by independent consultants?

- In what areas are the conclusions of the study different from the researcher's beliefs?

- To what extent do the final conclusions surprise the researcher? Where does he or she as a person disagree with the conclusions drawn from the study? Do these areas of disagreement have their roots in the source data?

\section{Presentation of results}

After the research is completed and the results have been described, the time comes to present them to a wider audience. This is an important stage with regard a wide range of issues that are not directly visible to the subjects of study but which are extremely important from the perspective of ethical analysis of the material. At this stage, one should consider the impact of the acquired knowledge on the studied group and its social environment in the context of the months, years and decades to come. Information that has been analyzed, described and made public as so-called "neutral knowledge" produced in good faith may, at some point, begin to take on a life of its own, with all the twists and turns that you can imagine, including irreversible changes in and disintegration of the study population.

The first matter concerns the researcher's responsibility for the consequences of the publicly disclosed conclusions. The researcher is responsible for the conclusions drawn, the form of which should be as objective as possible and justified by the source data. The researcher is a co-creator of the cultural identity of the elderly, due to the fact that this social group rarely takes the stage to speak about its own affairs. It is as a result of such research that whom seniors are in our world and what social significance is given to them is determined.

Two types of description are possible - the first is reproducing what seniors say and do, how they work, what they do not do, what they do not like, etc. It is possible, after Maria Ossowska (1947, p. 1), to describe this approach as a descriptive perspective. The second type describes seniors as the protagonists of stories created by the historians studying them; they are situated within the definitions and meanings that we give to them. How the senior will be treated as a member of a wider community will depend on the perspective adopted by the researcher for telling the story; such a perspective might be described as valorizing. Being aware of which of the two perspectives a researcher is operating with while interpreting and presenting the results allows him or her to carry 
out research that is more or less socially engaged research, i.e., by participating in solving social problems, even at the price of giving up the quest for objectivity (which, after all, is often purported to be illusory). It is in the moment of drawing conclusions and presenting the results that the researcher settles for one of two general paradigms objectivist vs engaged. In the latter, he or she can make moral assessments of the studied phenomenon without consequences. This research identification may occur in earlier stages of the research process, but it is only at the final stage that this attitude is expressed to the recipients of the research conclusions.

The main challenge associated with the publication of research results is protecting the elderly - i.e., the study's respondents - from the negative consequences of participating in the study at the hands of members of their social groups (for example, inhabitants of the same town, members of the same club or residents of the same care institution). Therefore, the presentation of the results should, like the acquisition of respondents for the study, comply with the principles of anonymity and privacy. Sometimes, in order to protect seniors, it is necessary to introduce fictionalization, which involves modifying personal data or the place of study in order to prevent recognition of the investigated person (Kubinowski, 2011, p. 350).

Another issue is the axiological impartiality of the researcher toward the reality described. The researcher is responsible not only for the moral course of the research procedures but also for the ideological perspective adopted, which affects the form of the final conclusions. It is worthwhile for the researcher to be aware of his or her subjectivity in perceiving and assessing the research situation and of his or her own impact on the content and course of the study, as well as the impact that the study exerts on the researcher himself or herself. This self-awareness can play an important role in the direct presentation of results during talks at conferences.

In the context of ethical considerations, the issue of the "moral entanglement of social facts" (Ostrowski, 2005, p. 169) should not be overlooked in the case of research into ethically and socially sensitive problems, which in relation to elderly people may concern their addictions, sex life, sexual orientation, attitudes toward violence and issues of sympathy toward, or dislike of, others. A decision must be made about which data to disclose and what to do with incomplete, unpopular and internally contradictory data.

At this stage of the research process, it's worth the researcher asking him- or herself the following ethical questions:

- What is the researcher's attitude - objectivist or engaged?

- What long-term effects will the research results have on the people studied?

- To what extent should data be fictionalized in order to protect respondents?

- To what extent are the presented results morally entangled? What issues should be clarified? What issues should be omitted for the good of the respondents?

\section{Summary}

Caring about ethics in research is an element that increases the quality of research (Flick, 2011). Some social researchers believe that a poorly planned research project is, by definition, unethical. However, there are those who suggest - especially in qualitative research that at the design stage of a study, it is impossible to plan for and resolve all issues, whether methodological or ethical (Ramcharan and Cutcliffe 2001). 
In research into old age, ethics is undoubtedly intended to protect all sides of a study the commissioning authority, the executor and the one being studied, from abuse. Additionally, in the case of studying the elderly, ethics aims to protect them in their weakness, dependence and disability.

The researcher is confronted with the need to answer the question about the importance of the ethical dimension of research at each stage of a study. He or she must determine whether the study will touch on the perspective of objectivity (corresponding to the truth), the good of respondents (protection of dignity) or ensuring the quality of research in terms of its correctness. Or, perhaps, the usefulness of the research should be the primary goal?

Constraining the freedom of the respondents and acting against their best interests are behaviors that are undoubtedly unethical in the study of the elderly. Moreover, using respondents to achieve goals of the researchers that are not related to research or distorting research findings during their interpretation are unacceptable activities that place the given research outside the sphere of ethically acceptable procedures. In this sense, the ethical competence of the researcher is an integral part of substantive competence, and methodological reflection must be accompanied by ethical reflection.

There are several basic rules that can insure that research is ethically sound:

- An analysis of potential gains and losses, of benefits and burdens, on the part of the researcher and respondents should contribute to the decision whether to join the research or withdraw from it.

- Informed consent means that no one should take part in the research without knowing what it means and without being able to express a refusal; misleading respondents should thus be avoided. Moreover, in the case of the elderly, information about the study should be provided in a clear and transparent way, in addition to ensuring that this information is well understood.

- During and after research, privacy, confidentiality and anonymity should be guaranteed and strictly observed.

- The research relationship should be based on appropriate treatment of respondents as subjects, with kindness, openness and respect.

- Basing conclusions and interpretations on source data that are obtained with due accuracy (without manipulation, omissions, overinterpretation or other distortions) should be the guiding principle in the analysis and presentation of the research results.

- The researcher should be aware of his or her own beliefs, attitudes, views, needs and expectations in the context of the research and should decide whether he or she is proceeding with an objectivist or engaged approach, with all the methodological and ethical consequences of this choice.

The social, medical and human sciences are deeply immersed in reflection on the human being, and scientists are both observers and participants in the research process. Researchers are constantly interacting with a complex and demanding environment that influences their research decisions both formally and informally. One important way to deal with these impacts is by following ethical principles. We might allow the following quote to testify to the complexity of ethical reflection in old age research:

It is the researcher's responsibility to act in an ethically acceptable manner, bearing in mind his own goals, his situation in the field, and the values and interests of the people involved. In other words, as researchers and at the same time recipients of research, we 
have to assess for ourselves what is right and what is undesirable in a given case. We should also be prepared to defend our decisions if they are questioned. We must understand that other people, despite our arguments, may have a different opinion that does not follow from some hidden motives. It is important that ethical issues are discussed in the public forum, as this will benefit researchers' awareness.

(Hammersley and Atkinson, 2000, pp. 289-290)

\section{References}

Association of Social Anthropologists (2011). Ethical guidelines for good research practice. ASA, UK.

Borkowski, A. (2013). Problemy etyczne w badaniach instytucji totalnych. International Letters of Social and Humanistic Sciences, 1. Available at: www.ceeol.com [Accessed 31 August 2019].

Brzeziński J. (2015). Metodologia badań psychologicznych. Warsaw: Wydawnictwo Naukowe PWN.

Cash, R., Wikler, D., Saxena, A. and Capron, A. (eds) (2009). Casebook on ethical issues in international health research. Geneva: WHO.

Chomczyński, P. (2006). Wybrane problemy etyczne w badaniach: Obserwacja uczestnicząca ukryta. Przegląd Socjologii Jakościowej, II(1).

Code of Ethics for Research Workers (2017). Polish Academy of Sciences, Warsaw.

Dąmbska, I. (1967). O narzędziach i przedmiotach poznania. Warsaw: PWN.

Dyoniziak, R. (1997). Sondaże a manipulowanie społeczeństwem. Kraków: Universitas.

Flick, U. (2011). Jakość w badaniach jakościowych. Warsaw: WN PWN.

Frankfort-Nachmias, C. and Nachmias, D. (2001). Metody badawcze w naukach spolecznych. Poznań: Zysk i S-ka.

Galewicz, W. (2009). O etyce badań naukowych. Diametros, 19.

Górniewicz, J. (2016). Wymiar etyczny w badaniach społecznych: Zaczyn dyskusji [The ethical dimension in social research: the beginning of discussion]. In: H. Kędzierska (ed.), Etyka jakościowych badań edukacyjnych. Olsztyn: Wydawnictwo Uniwersytetu warmińsko-Mazurskiego.

Hałas, E. (2010). Kulturowe źródła podmiotowości. In: E. Hałas and A. Kojder (eds), Socjologia humanistyczna Floriana Znanieckiego: Przestanie dla współczesności. Warsaw: Wydawnictwo Uniwersytetu Warszawskiego.

Hammersley, M. and Atkinson, P. (2000). Metody badań terenowych. Poznań: Zysk i S-ka.

Ingarden, R. (1987). Ksiązeczka o człowieku. Kraków: Wydawnictwo Literackie.

Jevons, W.S. (1960). Zasady nauki. Warsaw: PWN.

Kant, I. (2002). Groundwork for the metaphysics of morals. Ed. and trans. A.W. Wood. New Haven, CT: Yale University Press.

Kodeks Etyki Pracownika Naukowego (2013). PAN, Warsaw.

Kubinowski, D. (2011). Jakościowe badania pedagogiczne: Filozofia - Metodyka - Ewaluacja. Lublin: UMCS.

Nagel, E. (1970). Struktura nauki. Warsaw: Wydawnictwo Naukowe PWN.

Ossowska, M. (1947). Podstawy nauk o moralności. Warsaw: Czytelnik.

Ostrowski, Ł. (2005). Badanie ksenofobii jako dylemat etyczny. In: K. Zamiara (ed.), Etyczne aspekty badań społecznych. Poznań: Wydawnictwo Naukowe UAM.

Pilch, T. (1998). Zasady badań pedagogicznych. Warsaw: Wydawnictwo Żak.

Ramcharan, P. and Cutcliffe, J. (2001). Judging the ethics of qualitative research: considering the "ethics as process" model. Health and Social Care in the Community, 9(6), 358-366.

Such, J. (1972). O uniwersalności praw nauki. Szkoła Wyższa im. Pawła Włodkowica w Płocku, Warsaw.

Uhlenberg, P. (2009). International handbook of population aging. New York: Springer.

Walczak-Duraj, D. (2013). Etyczne standardy w badaniach socjologicznych: perspektywa humanizacyjna. Kwartalnik Humanizacja pracy, 2(272), Płock.

Znaniecki, F. (1919). Cultural reality. Chicago, IL: University of Chicago Press. 